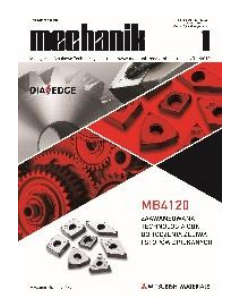

\title{
Mathematical model of the impact assessment of roughness and waviness deviations of races surfaces of rolling bearings on the level of generated vibration
}

\section{PAWEŁ ZMARZŁY *}

Dr inż. Paweł Zmarzły, pzmarzly@tu.kielce.pl, https://orcid.org/0000-0003-3717-1500 - Wydział Mechaniczny, Politechnika Świętokrzyska, Kielce, Polska

The article presents mathematical models allowing to describe the level of vibration generated by ball bearings 6304-2z type depending on the value of roughness and waviness deviations of inner and outer bearings races. This models will allow to estimate what type of shape deviations have dominant influence on the vibration level generated in specific frequency ranges.

KEYWORDS: ball rolling bearings, anderon, vibration, roundness, waviness

\section{Introduction}

In addition to durability and resistance torque, one of the most important operating parameters of bearings is the level of vibration generated. Excessive vibration of the rolling bearing may indicate its factory defect or damage propagation. As the vibration level increases, the noise of mechanisms increases and the bearing life decreases, which can result in failure. Therefore, the vibration analysis of rolling bearings is a powerful tool enabling the assessment of the state of new and working bearing nodes [1].

Many factors influence the value of vibration generated by rolling bearings. Among them, we can distinguish: radial clearance [2], basket imbalance, micro-damage of the raceway or rolling elements [3], impurities [4], value of the roundness deviation and the waviness of the raceway [5].

The simulation tests presented in [6] showed that the waviness generated by rolling bearings has a dominant influence on the level of vibrations generated by rolling bearings. Excessive waviness can significantly affect the performance characteristics of the bearing. This is especially visible in aerostatic bearings, where an increase in axial wave causes a decrease in bearing capacity and rigidity, as well as an increase in the friction coefficient [7]. The raceway waviness should also be analyzed for the possibility of transferring the oil film through rolling bearings [8].

The measurement procedure of the surface geometrical structure (SGP) parameters of a raceway and rolling elements is usually a destructive procedure, because it requires disassembly of the bearing elements to gain access to the raceway surface and the balls. Reassembly of rolling bearing elements is difficult or even impossible and involves the risk of assembly errors or contamination of the lubricant, which may result in excessive noise of the bearing during its operation. Therefore, similar treatments should be avoided.

Measurement of the level of generated vibrations is, in turn, a non-destructive and non-invasive procedure, and therefore commonly used in the bearing industry.

Although there is a lot of research work on the analysis of vibration of rolling bearings and the search for factors affecting the level of these vibrations $[6,7]$, few of these publications allow quantifying the impact of roundness and waviness deviations on the vibrations generated by bearings.

One way to do this is to develop general linear models based on regression equations. Due to these models, a researcher can approximately estimate the value of vibration in the frequency range of interest, as well as determine which type of deviation of the shape of the outer and inner raceway has a dominant impact on the level 
of vibration. It should be added that in many studies, the authors focus only on the analysis of roundness deviations, while they omit the waviness, while geometrical structure of the bearing raceway surface should be studied holistically.

\section{Research procedure}

In order to develop mathematical models, experimental tests of rolling bearings, commonly available on the market, were carried out. A group of 30 rolling bearings type 6304-2z was tested - their basic properties are shown in the table.

The research was carried out at the Kielce University of Technology as part of the "Miniature 1" project, financed by the National Science Center.

\section{TABLE. Basic properties of tested bearings}

\begin{tabular}{|c|c|c|}
\hline $\begin{array}{c}\text { rated dynaamic load capa- } \\
\text { city }\end{array}$ & $\mathrm{C}$ & $16.8 \mathrm{kN}$ \\
\hline nominal static load capacity & $\mathrm{C}_{0}$ & $7.8 \mathrm{kN}$ \\
\hline fatique load limit & $\mathrm{P}_{\mathrm{u}}$ & $0.335 \mathrm{kN}$ \\
\hline limiting speed & & $15000 \mathrm{~min}^{-1}$ \\
\hline
\end{tabular}

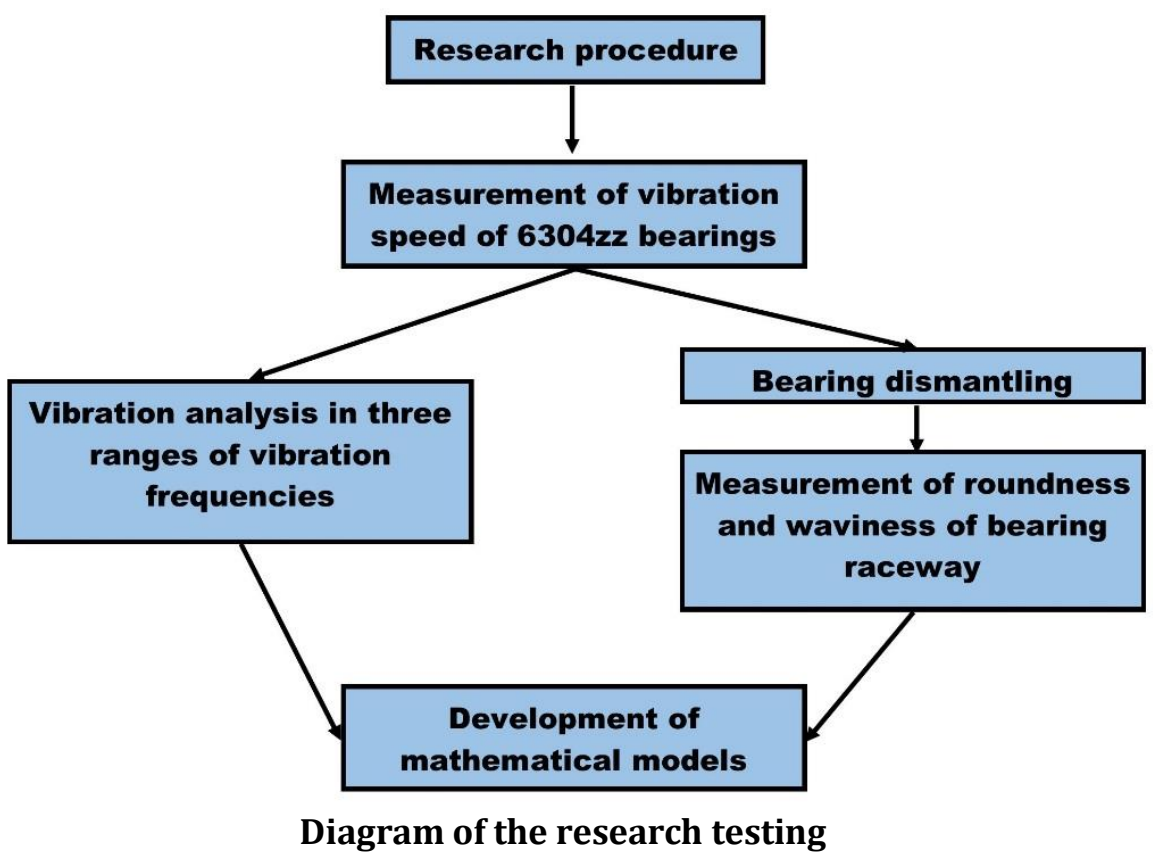

Individual steps of the research procedure aimed at determining the mathematical models for assessing the impact of track roundness and waviness deviations on the level of generated vibration are presented in the block diagram above.

The first stage of this procedure was measuring the vibration speed of a group of rolling bearings using the STPPD Anderometer measuring system, equipped with an SG 4.3 electrodynamic sensor from FAG [9].

In accordance with the requirements of the standards related to the measurement of vibration of rolling bearings, the tested bearing is accelerated to a rotational speed of $1800 \mathrm{~min}^{-1}$. Vibration velocity measurement is carried out under axial load in order to delete the clearance. The appropriate axial load is ensured by pneumatic pressure. Then the measuring signal is amplified, filtered and divided into three frequency bands, i.e.:

- low LB (low band) - from 50 to $300 \mathrm{~Hz}$,

- medium MB (medium band) - from 300 to $1800 \mathrm{~Hz}$,

- high HB (high band) - from 1800 to $10,000 \mathrm{~Hz}$.

Level of generated vibrations was expressed using the anderon (And) unit [5]. 
After measuring the vibration, the bearings were dismantled to gain access to the raceway surface. Then the roundness profile and the waviness of the inner and outer raceway of bearings were measured. To this end, the Talyrond 365 system from Taylor Hobson was used.

The measured profiles were properly filtered to obtain the roundness and wave deviation - RONt. Roundness was analyzed in the range of $2 \div 15$ waves/rev, and the waviness deviation - in the range of $16 \div 50$ waves/rev. Based on the results of the tests, mathematical models were taken into account for each vibration frequency range (LB, MB and $\mathrm{HB}$ ), taking into account the values of measured deviations.

\section{Mathematical models}

One way to quantify relationships between many independent variables and a dependent variable is to analyze general linear models based on the regression equation [10]. This type of model can be described by the general relationship:

$$
y=b_{0}+b_{1} x_{1}+b_{2} x_{2}+\ldots+b_{k} x_{k}
$$

where: $y$ - dependent variable (explained); $b 0$ - free component; $b 1, b 2, b k$ - regression coefficients; $x 1, x 2, x k$ independent variables (explanatory); $k$ - number of predictors.

The author of this paper examined the influence of SGP parameters of bearing raceways on the level of generated vibrations, which was analyzed in specific frequency ranges (LB, MB and HB). In this case, the predictors (independent variables) were the roundness deviation and the inner and outer race waviness of the rolling bearings. In total, four independent variables were studied. The dependent variable was the vibration value, analyzed in three frequency ranges. Preliminary analysis of the measurement results showed that the considered input parameters (predictors) are not correlated with each other. Therefore, it was possible to develop mathematical models in Statistica software. The regression coefficients were estimated using the least squares (LS) method.

Based on experimental research, the relationship (1) was transformed to obtain a general linear model, used to assess the impact of the roundness deviation value and rolling bearing raceway waviness on the level of generated vibrations:

$$
L B, M B, H B=b_{0}+b_{1} R O N t_{2-15}(P W)+b_{2} R O N t_{16-50}(P W)+b_{3} R O N t_{2-15}(P Z)+b_{4} R O N t_{16-50}(P Z)
$$

where: LB, MB, HB - vibration values in specific frequency ranges; $b 0$ - free word; $b 1, b 2, b 3, b 4$ - regression coefficients; RONt2-15 (PW) - inner race roundness deviation, analyzed in the range of $2 \div 15$ waves/rev; RONt16-50 (PW) - inner race wave deviation, analyzed in the range of $16 \div 50$ waves/rev; RONt2-15 (PZ) - outer race roundness deviation, analyzed in the range of $2 \div 15$ undulation/rev; RONt16-50 (PZ) - outer race wave deviation, analyzed in the range of $16 \div 50 \mathrm{u} / \mathrm{rev}$.

Based on the results of measurements, a general linear model was developed for the low frequency range of vibrations (LB), described by the relationship:

$L B=2,99+4,095 R O N t_{2-15}(P W)+8,465 R O N t_{16-50}(P W)++2,136 R O N t_{2-15}(P Z)+7,268 R O N t_{16-50}(P Z)$

The determination coefficient $R^{2}=0.7$ was obtained for the model described by equation (3). This means that $70 \%$ of dependent variables are explained. The level of significance of the examined model is equal to $p=$ 0.00003. Therefore, it can be concluded that the mathematical model of assessing the impact of treadmill SGP parameters on the vibration level, analyzed in the low frequency range, is statistically significant. From dependence (3) it follows that the increase in the roundness and wave deviation - both of the inner and outer raceways - causes an increase in the vibration value in the frequency range from 50 to $300 \mathrm{~Hz}$. The dominant influence in this case is the roundness deviation of the outer race and the deviation of the inner race corrugation, which is confirmed by the obtained high values of standardized regression coefficients (for roundness $\beta=0.69$, for waviness $\beta=0.27$ ).

General linear model for the medium range of vibration frequencies (MB) is: 
$M B=8,39-5,272 R O N t_{2-15}(P W)+1,537 R O N t_{16-50}(P W)++5,407 R O N t_{2-15}(P Z)-23,946 R O N t_{16-50}(P Z)$

For the model described by equation (4), the determination coefficient $R^{2}=0.58$ and the level of significance $p=0.00016$ were obtained, which also indicates that the model is statistically significant. Analyzing equation (4), it can be noticed that the increase in the inner race wave deviation and the outer race roundness deviation causes a decrease in the value of recorded vibrations in the frequency range $300 \div 1800 \mathrm{~Hz}$. On the other hand, an increase in the inner race wave deviation and an outer race roundness deviation causes an increase in the value of generated vibration. The dominance of the outer race is the roundness deviation - the standardized regression coefficient is $\beta=0.85$.

The regression equation obtained for vibration values recorded in the high frequency range (HB), i.e. $1800 \div 10000 \mathrm{~Hz}$, is as follows:

$H B=3,92-1,025 R O N t_{2-15}(P W)+1,537 R O N t_{16-50}(P W)++0,143 R O N t_{2-15}(P Z)-0,423 R O N t_{16-50}(P Z)$

For equation (5), the coefficient of determination is equal to $R^{2}=0.17$, and the level of significance $p=0.289$. This means that the developed mathematical model (5) is not statistically significant. In addition, the level of significance $p>0.05$ was obtained for all independent variables in the analyzed model (deviations of race roundness and waviness), which confirms the lack of statistical significance. Only $17 \%$ of all dependent variables are explained in this model. Therefore, it can be stated that the values of the deviations of the roundness and waviness of the raceways of the tested bearings do not significantly affect the values of vibration analyzed in the high frequency range.

\section{Summary}

Various factors affect the vibration values generated by rolling bearings. Due to their multitude, there is a need for a quantitative assessment of the significance of the impact of individual factors on the vibrations recorded in a specific frequency range. One way is to develop and analyze linear models based on regression equations. Based on these models, you can estimate the vibration values recorded in the selected frequency band. In addition, the analysis of regression equations allows the selection of factors having a dominant impact on the parameter being tested.

The main purpose of the research presented in this article was to assess the impact of roundness and wave deviation on the vibration level of rolling bearings. Vibrations were analyzed in three frequency ranges: low (from 50 to $300 \mathrm{~Hz}$ ), medium (from 300 to $1800 \mathrm{~Hz}$ ) and high (from 1800 to $10000 \mathrm{~Hz}$ ). As part of the analysis of measurement results, three mathematical models were developed (for each vibration frequency band).

Based on the results of the research, it can be stated that only models developed for the low and medium range of vibration frequencies are statistically significant, which proves that the deviations of the race roundness and waviness affect the vibrations recorded in given frequency ranges.

Analysis of the model developed for a low range of vibration frequencies indicates (which was to be expected) that an increase in the value of all measured deviations causes an increase in the value of generated vibration. On the other hand, in the case of the model developed for the medium frequency range, the vibration values decrease with the increase of the inner race wave deviation and the outer race roundness deviation. This may be the result of other factors not included in the model, such as differences in ball diameters or the presence of impurities.

The regression equation developed for the high frequency oscillation band proved to be statistically insignificant. Therefore, they should be omitted in the analysis of the impact of deviations on the level of generated vibrations.

Summing up the analysis of all models, it can be concluded that the most adequate are the models developed for the low and medium range of vibration frequencies. For these models, the deviation of the inner race roundness had the greatest impact on the values of generated vibrations. Considering this, the geometry of the inner ring should be analyzed in detail. In addition, based on the determined models and measured values of shape deviations, it is possible to estimate the approximate vibration value for a specific frequency range.

Results presented in this paper are an introduction to a broader study aimed at analyzing the factors affecting the level of vibration generated by bearings. The authors plan to extend models and test other types of bearings. 
The research was funded by the National Science Center under Action No. 2017/01/X/ST2/00155 entitled "Mathematical models for assessing the impact of selected parameters of the geometrical structure of active rolling bearing surfaces on the level of generated vibrations."

The paper was financed from funds for research and development work carried out by Fabryka Montażów Tocznych Kraśnik S.A. together with the Świętokrzyska University of Technology (project titled "Establishment of the R\&D Center at FŁT Kraśnik SA" under the Intelligent Development Operational Program 2014-2020) and co-financed from the European Regional Development Fund No. CBR/1/50$52 / 2017$ from 07.04. 2017, in which the results of the abovementioned research were used.

\section{REFERENCES}

[1] El-Thalji I., Jantunen E. "Fault analysis of the wear fault development in rolling bearings". Engineering Failure Analysis. 57 (2015): 470-482.

[2] Kaczor J. „Wpływ luzu w łożyskach kulkowych na nieprawidłową pracę wału trzypodporowego”. Zeszyty Naukowe Politechniki Śląskiej. 83 (2014): 117-126.

[3] Kiral Z., Karagülle H. "Vibration analysis of rolling element bearings with various defects under the action of an unbalanced force". Mechanical Systems and Signal Processing. 20 (2006): 1967-1991.

[4] Mitrovica R.M., Miskovica Z.Z., Djukica M.B., Bakica G.M. "Statistical correlation between vibration characteristics, surface temperatures and service life of rolling bearings - artificially contaminated by open pit coal mine debris particles". Procedia Structural Integrity. 2 (2016): 2338-2346.

[5] Adamczak S., Zmarzły P. "Influence of raceway waviness on the level of vibration in rolling-element bearings". Bull. Pol. Ac.: Tech. 65, 4 (2017): 541-551.

[6] Liu W., Zhang Y., Feng Z.-J., Zhao J.-S., Wang D. "A study on waviness induced vibration of ball bearings based on signal coherence theory". Journal of Sound and Vibration. 333 (2014): 6107-6120.

[7] Wang X., Xu Q., Wang B., Zhang L., Yang H., Peng Z. "Effect of surface waviness on the static performance of aerostatic journal bearings". Tribology International. 103 (2016): 394-405.

[8] Ren Z., Wang J., Guo F., Lubrecht A.A. "Experimental and numerical study of the effect of raceway waviness on the oil film in thrust ball bearings". Tribology International. 73 (2014): 1-9.

[9] Adamczak S., Stępień K., Wrzochal M. "Comparative study of meas-urement systems used to evaluate vibrations of rolling bearings". Procedia Engineering. 192 (2017): 971-975.

[10] Muciek A. „Wyznaczanie modeli matematycznych z danych eksperymentalnych”. Wrocław: Oficyna Wydawnicza Politechniki Wrocławskiej, 2012 